\title{
As bibliotecas nacionais latino americanas e o capital social
}

Deborah Medeiros

Mestre em Gestão de Unidades de Informação pelo Programa de Pós-Graduação em Gestão da Informação (PPGInfo) da Universidade do Estado de Santa Catarina (UDESC)

Elaine Rosangela de Oliveira Lucas

Doutora em Ciência da Informação pela Universidade de São Paulo (USP), Docente do Programa de Pós-Graduação em Gestão da Informação (PPGInfo) da Universidade do Estado de Santa Catarina (UDESC)

http://dx.doi.org/10.1590/1981-5344/2754

Estudo que pretende analisar o uso da web social nos serviços das bibliotecas nacionais latino americanas e as formas de fomentar Capital Social em sua comunidade. Buscou-se verificar quais mídias sociais as bibliotecas nacionais usam, avaliando como adaptam aos serviços das bibliotecas e como as utilizam para fomentar o Capital Social, adotando-se para isso a teoria do fator whuffie. Utilizou-se a coleta e mapeamento de mídias sociais e observação não participante para a análise dos websites das Bibliotecas Nacionais analisadas. Como resultado, a pesquisa constatou que as Bibliotecas Nacionais em sua grande maioria utilizam seus sites e bibliotecas digitais para oferecer serviços e fomentar Capital Social entre seus interagentes. Por fim, conclui-se que as bibliotecas analisadas ainda utilizam suas mídias sociais na internet para fins administrativos e de divulgação, e observa-se que, através de algumas práticas identificadas nas bibliotecas analisadas nesta pesquisa, as demais bibliotecas podem buscar novas formas e possibilidades de interação dos seus serviços com seus interagentes por meio dessas mídias e de seus websites.

Palavras-chave: Bibliotecas Nacionais; Web social; Fator Whuffie; Capital social; Mídias sociais. 


\section{The latin american national libraries and social capital}

This study aims at analyzing the use of the social web for the services of Latin American national libraries and ways to promote social capital in their community. We sought to determine which social media are used by the national libraries evaluating how they adapt to the library services and how they use them in order to promote social capital adopting therefore the theory of the Whuffie factor. We used the collection and mapping of social media as well as non-participant observation for the analysis of the examined national libraries' websites. As a result the survey found that most national libraries use their websites and digital libraries to offer services and foster social capital among their interactors. It is subsequently concluded that the analyzed libraries also employ their web-based social media for administrative and dissemination purposes, and it is observed that, through determined practices identified in the libraries which were analyzed in this research, the other libraries may seek new ways and possibilities of interaction between their services and their interactors through these media and their websites.

Keywords: National libraries; Social web; Whuffie fator; Social capital; Social Media.

Recebido em 31.03.2016 Aceito em 20.11.2016

\section{Introdução}

Com a nova cultura informacional, um dos grandes desafios está em organizar e recuperar informações de qualidade com fácil acesso aos interagentes ${ }^{1}$. Assim, bibliotecários e bibliotecas devem estar cada vez mais preparados para essa nova realidade informacional, desenvolvendo produtos e serviços que busquem atingir efetivamente os objetivos de seu papel social, disponibilizando informações ao seu público.

As Bibliotecas Nacionais são representativas dentro de seus países. São guardiãs do conhecimento e do patrimônio cultural de sua nação, como um repositório bibliográfico, zelando por obras raras, detentora do

\footnotetext{
${ }^{1}$ Foi adotado o termo interagente em lugar de usuário, conforme proposta de Corrêa (2014), pois representa
} de maneira mais adequada a proposta deste estudo. 
depósito legal e cuidando dos direitos autorais. Hoje as bibliotecas nacionais fazem mais do que apenas zelar pelo patrimônio bibliográfico de seu país: elas também se preocupam com o acesso e a divulgação da informação. Muitas bibliotecas nacionais disponibilizam suas obras raras digitalizadas, oferecendo acesso indiscriminado de seus documentos à população.

Se as bibliotecas nacionais são os repositórios bibliográficos públicos da produção cultural de seus países, e também como biblioteca representante de uma nação, espera-se uma postura inovadora que possa ser seguida pelos outros segmentos de bibliotecas de seus países, já que muitas estão ligadas diretamente aos seus maiores órgãos culturais.

O direito à informação é fundamental para o desenvolvimento humano e as bibliotecas têm papel importante no fomento e no acesso à educação e conhecimento, segundo a Organização das Nações Unidas para a Educação, a Ciência e a Cultura (UNESCO, 1994). As bibliotecas nacionais, tendo em vista seu caráter público, também devem ser um centro de informações acessível aos seus interagentes, oferecendo seus serviços de forma igualitária e atualizada, cumprindo seu papel social. Assim, elas podem atender à sua comunidade (neste caso, seu país) e participar efetivamente do crescimento pessoal e social destes indivíduos, promovendo o Capital Social.

O conceito de Capital Social não é novo, tendo sido usado pela primeira vez por Hanifan, em 1916 (MATOS, 2009, p. 34). No entanto, a primeira análise sistemática do conceito é atribuída a Pierre Bourdieu, com a publicação do artigo Le capital social: notes provisoires, publicado em 1980. Neste artigo o autor definiu Capital Social como sendo

O conjunto de recursos atuais ou potenciais que estão ligados à posse de uma rede durável de relações mais ou menos institucionalizadas de interconhecimento e de inter-reconhecimento ou, em outros termos, à vinculação a um grupo, como conjunto de agentes que não somente são dotados de propriedades comuns (passíveis de serem percebidas pelo observador, pelos outros ou por eles mesmos), mas também são unidos por ligações permanentes e úteis (BOURDIEU, 2011, p. 67).

Hillenbrand (2005, p. 9) indica que "[...] existe um entendimento de que a biblioteca constrói Capital Social quando oferece um espaço que, utilizado por diferentes grupos sociais da comunidade, acomoda diversas necessidades e encoraja a interação social e confiança".

Quando a biblioteca se utiliza de tecnologias para disseminar seus documentos e informações, normalmente ela caminha em direção a melhoria da qualidade e da acessibilidade de seus serviços.

Para Warschauer (1996, p. 213), a internet oferece oportunidades para a comunicação e a associação das pessoas, fortalecendo e desenvolvendo vínculos sociais fracos, sendo ela um meio natural para o fortalecimento das conexões sociais. 
Ver o Capital Social como um fator de mudança implica em uma observação do papel da biblioteca como fomentadora deste capital com seus interagentes. A preocupação das bibliotecas em fortalecer o Capital Social é oportuna na dimensão das políticas públicas oferecidas e em sua abrangência, principalmente quando estão em ambiente virtual.

Dessa forma, as bibliotecas que mantêm serviços digitais devem observar como oferecer serviços de qualidade e que promovam o desenvolvimento do Capital Social. Para Hillenbrand ${ }^{2}$ (2005 apud MACIEL FILHO, 2010, p. 9), as bibliotecas podem criar Capital Social de várias maneiras: proporcionando o engajamento cívico, quebrando barreiras sociais e encorajando a tolerância, apoiando os ideais democráticos, disponibilizando informação sem custo para todos os cidadãos e promovendo a alfabetização digital, criando a cidadania informada, induzindo a participação entre comunidades, encorajando a confiança por meio da inclusão social, facilitando o diálogo local e disseminando as estatísticas locais, disponibilizando espaço público onde os cidadãos possam trabalhar juntos em problemas pessoais, incentivando a participação comunitária. Quando as bibliotecas buscam atender esses objetivos sociais, facilitam a interação social e a confiança em seus interagentes, assim, promovem o crescimento do acesso igualitário a informação e do senso de igualdade, contribuindo diretamente para o Capital Social (MACIEL FILHO, 2010, p. 5).

Essa responsabilidade social se intensifica dentro dos espaços virtuais de compartilhamento e interação, caracterizados pelo advento de uma cultura de participação na $w e b$, onde, consequentemente, encontramos um maior envolvimento dos indivíduos, buscando e produzindo informação, e isso se deve ao aumento e à facilidade dos usos das tecnologias de informação e comunicação. Toda essa produção gera uma miscelânea de informações, na qual o próprio autor classifica a informação, que nem sempre é encontrada facilmente. Se os interagentes estão cada vez mais presentes, a Biblioteca deve se abrir a esse ambiente, estruturar laços e criar uma relação de confiança. A utilização das tecnologias sociais, quando bem usadas, estreitam os laços entre os interagentes e a biblioteca.

Encontram-se muitas definições para usos de tecnologias em bibliotecas, popularmente definidas no uso da web 2.0, termo utilizado para denominar os novos recursos da web (World Wide Web), utilizado inicialmente por O’Reilly (2005). Na primeira geração da web, os interagentes usufruíam do conteúdo de forma limitada, sem grandes interações. O difícil acesso por parte do público em geral colaborava para essa limitação. Os conteúdos eram estáticos e seu maior uso era feito por empresas. A grande mudança no surgimento da web 2.0 é a interatividade com o interagente, onde se criou a cultura da colaboração. Os conteúdos passaram a ser produzidos pelos próprios internautas e as mídias sociais são o fenômeno da web 2.0.

\footnotetext{
${ }^{2}$ HILLENBRAND, C. Public libraries as developers of social capital. APLIS, v. 18, n. 1, p. 4-12, mar. 2005.
} 
Hoje já encontramos definições para a web 3.0, terceira geração da internet, também chamada web semântica, que permite uma maior integração do mundo físico com o virtual. O termo foi criado pelo jornalista Markoff do The New York Times e se caracteriza por seu conteúdo semântico, organizado e personalizado para atender melhor a cada interagente.

Deste modo, vislumbram-se grandes possibilidades para as bibliotecas em todos os segmentos com a utilização dos recursos de web 3.0: educação, disseminação, informação de qualidade, colaboração, acessibilidade e promoção do Capital Social. Como afirma Belling, seu uso justifica-se para "facilitar a disseminação de conteúdo gerado pelo utilizador e a colaboração, promovendo e tornando as bibliotecas acessíveis" (BELLING, 2011, p. 6, tradução nossa). A construção da biblioteca 3.0 é de extrema importância enquanto espaço de aprendizagem formal e informal.

Entre 2010 e 2011, Anna Belling e colaboradores desenvolveram o relatório Exploring library 3.0 and beyond, apresentado após estudos na biblioteca estadual e na rede de bibliotecas de Victoria (Austrália), onde fizeram recomendações de uso da web 3.0 para as bibliotecas públicas daquele país. (BELLING et al., 2011). Seu objetivo foi analisar os impactos das mudanças nos serviços de bibliotecas públicas na próxima década. Em suas recomendações, encontram-se sugestões possíveis, acessíveis e econômicas para a construção de serviços diferenciados aos interagentes das bibliotecas públicas, e demonstra a importância da biblioteca pública no seu papel social em oferecer informação a todos para promover a inclusão social, atualizar-se ao meio em que está inserida.

As atividades da web 3.0 estão presentes no cotidiano das pessoas. Dispositivos móveis aumentaram o acesso às informações, onde as necessidades informacionais são sanadas em um clique.

O continente latino americano apresenta situações econômicas e culturas diversas, bem como formas diferentes de trabalhar a educação. É necessário investigar como as bibliotecas nacionais vêm desenvolvendo seus serviços diante das novas tecnologias de informação e conhecimento, em especial os referentes à web 3.0, principalmente buscando entender as diferenças sociais e as contribuições desses serviços na construção do Capital Social por parte destas bibliotecas.

Nesse sentido, justifica-se investigar como as bibliotecas nacionais usam as mídias sociais e tecnologia, utilizadas em seus serviços e qual a relação desses serviços com o fortalecimento do Capital Social dessas bibliotecas.

Diante da importância de serviços inovadores nas bibliotecas, é igualmente importante a reestruturação dos serviços de bibliotecas nacionais, como detentoras da produção do conhecimento do país, no sentindo de humanizar e aproximar seus serviços do cidadão. Além do papel de guardiã do conhecimento, na sociedade atual as bibliotecas nacionais devem servir de exemplo de práticas e disseminação do 
conhecimento para as demais bibliotecas, justo que, em grande maioria, fazem parte do sistema de bibliotecas de seu país.

Apresentar como as bibliotecas nacionais, localizadas no continente latino americano, desenvolvem e oferecem produtos e serviços a partir do uso de web 3.0 e identificar as relações desses serviços com o acumulo do Capital Social dessas bibliotecas, é a inquietação que norteia este estudo. Com base nisso, serão verificadas quais as bibliotecas nacionais deste continente que utilizam os recursos de web 3.0 para oferecer serviços que fomentem Capital Social; serão analisadas quais bibliotecas nacionais utilizam suas redes sociais para fortalecer o Capital Social com seus interagentes, sob a ótica do fator whuffie $^{3}$; serão observadas as relações entre os serviços oferecidos e o acúmulo do Capital Social por parte das BNs; e por fim, serão identificados os serviços ofertados pelas bibliotecas nacionais que fomentam Capital Social.

\section{Opções e procedimentos metodológicos}

Nesta pesquisa a observação não participante foi essencial para a verificação dos websites e mídias sociais buscando os serviços que fomentassem Capital Social de acordo com nossas unidades de análise, já que a pesquisa não adotou questionário para coletar dados da instituição e dos seus interagentes. A base teórica da pesquisa é construída a partir dos conceitos de construção de Capital Social, a teoria do fator Whuffie de Hunt (2010) e dos critérios de Capital Social estabelecidos por Hillenbrand (2005).

Inicialmente, se identificou os perfis de mídias sociais de cada biblioteca, analisando com o auxílio de softwares, seus níveis de interação e engajamento com os interagentes, e como sua interação cria relacionamentos autênticos e contribui para construção do seu fator Whuffie dentro de suas comunidades. Posteriormente, por meio da observação não participante - entre julho e setembro de dois mil e quinze, se analisou os serviços ofertados nos websites das bibliotecas e nas mídias sociais, se esses serviços obedeciam algum dos itens apontados por Hillenbrand (2005) como promotor de Capital Social.

Para a compreensão dos valores construídos nas mídias sociais, vale ressaltar que o ato de curtir, compartilhar ou retweetar (RT, no caso do Twitter), comentar ou responder (reply, no caso do Twitter), favoritar, são ações de interação nas mídias sociais, representam relações de conversação entre as partes envolvidas, e constroem conexões associativas (RECUERO, 2014). Para Recuero (2014, p. 115), a conversação mediada por computador é uma apropriação, em que há a adaptação dos meios textuais para fins da conversação. As mídias sociais

30 termo Whuffie foi atribuído pelo escritor Cory Doctorow em seu livro de ficção científica "Down and out in the magic kingdom", de 2003. Já Tara Hunt (2010), em seu livro "O Poder das redes sociais: como o fator whuffie - seu valor no mundo digital - pode maximizar os resultados de seus negócios", de 2010, define o Whuffie como "a culminação da sua reputação, a influência, o capital de conexão, o seu atual e potencial acesso as ideias, talentos e recursos, o acúmulo de favores e realizações" (HUNT, 2010, p. 28). 
traduzem o meio social para o digital, gerando novas formas de conexões e conversação, cada rede com seu método particular para a criação dos laços sociais entre os indivíduos. A grande característica das conversações digitais criadas nas mídias sociais é que elas permanecem nesses espaços, são buscáveis e replicáveis, mesmo quando os interagentes não estão online. Assim, elas são reproduzidas facilmente por outros interagentes, espalham-se pela rede entre diversos grupos, migram e tornam essas conversações mais públicas, geram debates, ampliam ideias e opiniões (RECUERO, 2014, p. 116).

Já que cada mídia social possui sua linguagem para conversação, analisamos os dados de cada mídia social utilizada pelas bibliotecas nacionais, buscando evidenciar a presença e participação das bibliotecas em suas redes. O uso das mídias sociais na internet, de acordo com sua mediação, oferece aproximação a recursos e pessoas que "proporcionam aos atores acesso a tipos diferentes de Capital Social - que não estariam acessíveis de outras formas" (RECUERO; ZAGO, 2009, p. 84).

Para analisar as bibliotecas nacionais na mídia social Facebook, coletamos as métricas com o auxílio do software de monitoramento e análise de mídias sociais LikeAlyzer ${ }^{4}$, que oferece métricas sobre fanpages do Facebook utilizando seu endereço. Os dados levantados pelo sistema são divididos em informações, a performance e dados sobre as postagens das páginas.

Quanto aos dados coletados pelo software LikeAlyzer usados para análise nessa pesquisa foram: Quantidade de likes da página (curtidas) Checkins (registro de geolocalização feito por quem visita o ambiente físico da biblioteca, mas registra no Facebook) - pessoas falando sobre a página (People talking about this - PTAT) - taxa de engajamento (o número de PTAT dividido pelo número total de likes) - média de postagens diárias - média de likes - comentários e compartilhamentos por postagens - tipos de interação nas postagens (imagem, anexo, vídeo ou comentário de posts) - tamanho das postagens e o uso de hashtags (considerando que o uso aumenta a visibilidade das postagens).

Quanto a análise das contas das bibliotecas nacionais na mídia social Twitter utilizou-se o software de monitoramento e análise de mídias sociais TweetStats ${ }^{5}$, que oferece métricas de contas no Twitter analisando desde sua criação. Dos dados coletados para análise nessa pesquisa foram: número de tweets (postagens no Twitter) - média de tweets por dia e por mês - média de replies (respostas aos interagentes, índice de conversação) - média de retweets (RTs, o compartilhamento de tweets) e as interfaces usadas para gerar tweets (analisando se o conteúdo foi criado na própria rede ou apenas replicado postagens de outras redes, como Facebook e Instagram).

Para as outras mídias sociais das bibliotecas, a coleta de dados foi feita diretamente nas mídias. Quanto aos canais das bibliotecas no Youtube, observou-se a quantidade de vídeos postados pelas bibliotecas,

\footnotetext{
${ }^{4}$ Disponível em: <http://likealyzer.com/>. Acesso em: 15 dez. 2015.

${ }^{5}$ Disponível em: <http://www.tweetstats.com/>. Acesso em: 15 dez. 2015.
} 
número de inscritos no canal e quantidade de visualizações do canal. Para a mídia social Instagram e Flickr observou-se a quantidade de seguidores e de imagens postadas. Para a mídia social Pinterest, observou-se a quantidades de seguidores, de pins (publicações ou compartilhamento de imagens ou vídeos), e de painéis (murais temáticos).

Acredita-se que quanto mais ativo nas mídias sociais, maior o engajamento do público com a instituição, o que torna importante verificar como as bibliotecas estão utilizando e construindo seu Whuffie através do uso de mídias sociais.

\section{Apresentação da análise nas bibliotecas nacionais}

Apresentamos os dados coletados nos perfis das vinte bibliotecas pesquisadas, como suporte para a interpretação dos dados. Além da análise das mídias sociais das bibliotecas, analisados a ótica de construção de Capital Social nas mídias sociais - o fator Whuffie - realizou-se uma análise qualitativa, através de observação não participante dos serviços online ofertados nos websites das bibliotecas nacionais que construíssem algum tipo de Capital Social, com base em Hillenbrand (2005), conforme descrito anteriormente.

Para uma análise geral do uso de mídias sociais pelas bibliotecas pesquisadas, apresenta-se o quadro a seguir.

Quadro 1 - Mídias Sociais usadas pelas Bibliotecas Nacionais Latino Americanas

\begin{tabular}{|l|l|l|l|l|l|}
\hline & & & \\
\hline
\end{tabular}

Fonte: Dados da pesquisa. 


\subsection{Biblioteca Nacional da Argentina}

A Biblioteca Mariano Moreno ${ }^{6}$, biblioteca nacional da Argentina, possui um website institucional próprio, atualizado, e com informações referentes a seu acervo, eventos e outras notícias sobre a biblioteca. Mantém atualizado uma página no Facebook na categoria organização governamental desde 2010, atualizada frequentemente e uma conta no Twitter.

A biblioteca mantém um número elevado de pessoas interagindo com a página no Facebook, vide seu número de curtidas e checkins. Sua interação está na divulgação de serviço e notícias através de sua timeline, mas sua interação por meio de curtidas e respostas é baixa. O que ficou evidente na análise das redes é que a biblioteca utiliza o Twitter com o foco de divulgação, em sua maioria de tweets enviando as mesmas publicações do Facebook para o Twitter.

Quanto aos seus serviços, a biblioteca faz parte da Biblioteca Digital do Patrimônio Ibero-americano (BDPI), juntamente com a Bolívia, Brasil, Chile, Colômbia, Cuba, El Salvador, Espanha, Panamá, Portugal e Uruguai, que pretende resguardar o patrimônio cultural e criar um portal que permita a consulta unificada para acesso aos recursos digitais de todas as bibliotecas participantes. É uma ferramenta fundamental na construção e fortalecimento do Espaço Cultural Ibero-americano, e enquanto participantes dessa biblioteca, as Bibliotecas Nacionais criam Capital Social inclusivo e exclusivo, já que encorajam a participação com outras comunidades, como também facilitam o diálogo local oferecendo material sobre a cultura Ibero-americana.

Além disso, a Biblioteca Nacional Mariano Moreno possui uma biblioteca digital mundial, com mais de 12.000 mil artigos sobre 193 países num período compreendido entre 8000 a.C a 2000 d.C. A biblioteca também mantém sua "Biblioteca Digital Trapalanda" que possui os arquivos raros da biblioteca nacional, nos formatos: audiovisual, arquivos sonoros, documentos históricos, exlibris, folhetos, fotografias, livros, manuscritos, mapas, materiais gráficos, música impressa e manuscrita, periódicos, publicações da Biblioteca Nacional e revistas. Além das obras raras, a Trapalanda dispõe projetos culturais da biblioteca, como suas produções para a televisão, realizado em coprodução com canais públicos, para a divulgação e discussão de trabalhos, livros e viagens culturais. Entre as cinco produções já executadas pelo projeto, destaca-se uma série de aulas abertas por Ricardo Piglia dedicado a revisitar a obra literária de Jorge Luis Borges. As aulas são transmitidas na televisão e disponibilizadas no acervo da biblioteca digital. A premissa dos projetos digitais da Biblioteca Nacional Mariano Moreno, a Biblioteca Digital Trapalanda e a Biblioteca Digital Mundial, é disponibilizar informação sem custo para todos os cidadãos, promovendo cidadania e alfabetização digital, indicativo de construção de Capital Social na visão de Hillenbrand (2005).

${ }^{6}$ Disponível em: <http://www.bn.gov.ar/>. Acesso em: 15 dez. 2015. 


\subsection{Biblioteca Nacional da Bolívia}

O Archivo y Biblioteca Nacionales de Bolívia ${ }^{7}$, possui um website institucional próprio, subdivido entre a Biblioteca Nacional e o Arquivo Nacional da Bolívia. Mantém uma página oficial de categoria organização governamental desde 2014, uma conta no Twitter e um canal de vídeos no Youtube desde março de 2015.

A página da Biblioteca ainda é nova e funciona como um espaço de divulgação dos serviços da biblioteca, sua interação é baixa. Quanto ao uso do Twitter, em sua maioria, funciona como um replicador das publicações do Facebook, inclusive com links para as próprias postagens da página. O canal do Youtube conta com vídeos sobre a biblioteca e o arquivo nacional e eventos. Como o uso das mídias sociais pela biblioteca da Bolívia ainda é recente, nota-se um baixo engajamento e resposta em suas redes.

Quanto aos serviços, a Biblioteca Nacional faz parte da Biblioteca Digital do Patrimônio Ibero-ameriano, assim como a Biblioteca Nacional da Argentina. Sua Biblioteca Digital está linkada diretamente a base de dados da Biblioteca Digital do Patrimônio Ibero-ameriano. Em seu website, oferece uma série chamada Sublevación General de Indios, uma série composta por documentos e arquivos relacionados à revolta dos índios entre 1780-1782, que revolucionou os territórios do Vice-reino do Peru e do Rio de La Prata na América. Esse serviço adequa-se a condição de apoiar os ideais democráticos, oferecendo informação histórica, promovendo uma cidadania informada, de acordo com Hillenbrand (2005).

\subsection{Biblioteca Nacional do Brasil}

A Fundação Biblioteca Nacional ${ }^{8}$ possui website institucional próprio, atualizado, com informações de seus serviços, acervo, projetos e exposições. Possui uma página no Facebook de categoria organização governamental, atualizada frequentemente, uma conta na mídia social Twitter, um canal no Youtube desde 2011 e um blog institucional.

A biblioteca mantém um número elevado de pessoas interagindo com a sua página no Facebook e em sua conta no Twitter, algo esperado já que a Biblioteca Nacional é considerada pela UNESCO como uma das dez maiores bibliotecas nacionais do mundo. Sua interação está na divulgação de serviço, eventos e notícias através de sua timeline, possui um bom percentual de interação através de curtidas, compartilhamentos e comentários. Quanto aos tweets, nota-se uma boa interação por parte da biblioteca, já que $21,63 \%$ de seus tweets são retweets (compartilhamento de tweets). A biblioteca utiliza o Twitter desvinculado de sua conta no Facebook e dá atenção especial a essa mídia social. Quanto a seu canal no Youtube, contém vídeos diversos produzidos pela biblioteca, mas não é atualizado há 3 anos.

\footnotetext{
${ }^{7}$ Disponível em: <http://www.archivoybibliotecanacionales.org.bo/>. Acesso em: 15 dez. 2015.

${ }^{8}$ Disponível em: <http://www.bn.br/>. Acesso em: 15 dez. 2015.
} 
Quantos aos seus serviços online, a Fundação Biblioteca Nacional mantém a Biblioteca Nacional Digital, responsável pela digitalização do acervo impresso e raro da biblioteca, com mais de 1.047.641 documentos disponíveis para livre acesso, uma amostra significativa do patrimônio documental depositado na Biblioteca Nacional. Dividida entre a BN Digital e a Hemeroteca Digital (periódicos), a Biblioteca Nacional disponibiliza em seu acervo digital cartografia, iconografia, manuscritos, música e arquivo sonoro, obras gerais, obras raras, periódicos e acervo de referência. Vale ressaltar os artigos, os dossiês e exposições disponíveis na BN Digital. Através do portal da BN Digital, os visitantes podem acompanhar virtualmente as mais importantes exposições realizadas nos últimos anos pela Biblioteca Nacional, visitas guiadas ao acervo através de percursos temáticos constituídos nos dossiês de documentos e textos inéditos, produzidos especialmente para o projeto.

Além disso, seu acervo digital compõe a Biblioteca Digital do Patrimônio Ibero-ameriano, assim como as bibliotecas nacionais da Argentina e Bolívia. Ainda, a Fundação Biblioteca Nacional mantém o projeto Brasiliana Fotográfica, com o intuito de dar visibilidade, fomentar o debate e a reflexão sobre seu acervo fotográfico, como patrimônio digital e fonte primária de pesquisa. Mantém exposições temáticas fotográficas.

De acordo com os indicativos de construção de Capital Social apontados por Hillenbrand (2005), a Fundação Biblioteca Nacional em seus serviços digitais fomenta Capital Social das seguintes formas: apoiando ideias democráticas, oferecendo informação sem custo para todos os cidadãos, promovendo a alfabetização digital e criando uma cidadania informada, facilitando o diálogo local e criando Capital Social exclusivo, através de um ambiente virtual inclusivo.

\subsection{Biblioteca Nacional do Chile}

A Biblioteca Nacional de Chile $e^{9}$ possui website institucional próprio, onde divulga seus serviços, notícias da biblioteca e da cultura chilena. Mantém uma página no Facebook na categoria organização governamental desde 2008 e uma conta no Twitter.

A Biblioteca Nacional do Chile possui um grande número de interagentes em suas mídias sociais e altas taxas de engajamento, através de curtidas, compartilhamentos e comentários no Facebook e principalmente no Twitter onde a grande maioria dos tweets gerados por seu perfil são de respostas ou compartilhamento de tweets (RTs). Vale ressaltar que seu uso no Twitter é com conteúdo gerado diretamente na rede e não como replicador de informações de sua fanpage no Facebook.

Quanto aos seus serviços, a biblioteca possui uma biblioteca digital e também participa da Biblioteca Digital del Patrimonio Ibero-ameriano, juntamente com Argentina, Bolívia e Brasil, já citados. Em sua coleção digital, disponibiliza reproduções completas ou parciais de arquivos de

\footnotetext{
${ }^{9}$ Disponível em: <http://www.bibliotecanacional.cl/>. Acesso em: 15 dez. 2015.
} 
texto, vídeo, imagem e áudio digitalizados de seu acervo. Dentro seus serviços, disponibiliza uma sessão chamada Memória Chilena, com acervo digital especializado sobre a identidade cultural do Chile. Também oferece visitas virtuais, através de recursos visuais que imprimem ao interagente a sensação de estar visitando a própria biblioteca, por duas salas temáticas: a sala Medina, que disponibiliza um catálogo digital próprio do fundo bibliográfico de obras raras sobre o Chile, e a sala de prensa, que armazena a história da imprensa nacional, com acervo dividido entre periódicos e revistas, oferecendo ao leitor as revistas mais importantes do país. Com esses serviços, a Biblioteca Nacional do Chile fomenta Capital Social quando disponibiliza informação sem custo para todos os cidadãos, apoiando os ideais democráticos, criando uma cidadania informada.

\subsection{Biblioteca Nacional da Colômbia}

A Biblioteca Nacional de Colômbia ${ }^{10}$ possui website institucional próprio, onde apresenta seus serviços, notícias da biblioteca e culturais do país, exposições. Mantém uma página no Facebook na categoria organização governamental desde 2009, uma conta no Twitter na qual os tweets também são exibidos na página principal do website, com a opção do interagente enviar tweets para a biblioteca diretamente do website, uma conta no Youtube desde 2009 e um blog institucional.

A biblioteca mantém um grande número de pessoas interagindo com a sua página no Facebook e em sua conta no Twitter. Quanto ao Facebook, a biblioteca tem um nível alto de interação, quando se observa sua média de postagens e comentários, curtidas e compartilhamentos. Já no Twitter, além do número elevado de postagens diárias, observa-se que metade de suas postagens são compartilhamento de informações de outros seguidores (RTs). O fato da biblioteca manter um espaço na página principal do seu website para o Twitter e encorajar a conversação feita diretamente do website fortalece o poder da rede como um canal de comunicação entre a biblioteca e a comunidade. Seu canal no Youtube é alimentado com uma média de quatro vídeos mensais, com vídeos produzidos pela biblioteca, de eventos ou de seu acervo, com uma boa média de visualizações por vídeo. Além de manter um blog integrado ao seu website, a biblioteca mantém um projeto de uma wiki própria (conjunto de páginas interligadas, e cada uma delas pode ser visitada e editada por qualquer pessoa), a BNWiki, La wiki de la Biblioteca Nacional de Colombia. Foi criada com o intuito de ser um inventário dos conteúdos digitais produzidos pela biblioteca sobre suas coleções e para resguardar a memória institucional. A wiki pode ser alimentada pelo público, que solicita um registro à biblioteca para criar, editar textos e imagens.

Quanto aos serviços do website, a biblioteca disponibiliza uma coleção digital, que está subdivida em documentos digitais, coleções temáticas, exposições virtuais, tesouros da Biblioteca Nacional, ferramentas de aprendizagem, laboratório digital, exposições virtuais,

\footnotetext{
${ }^{10}$ Disponível em: <http://www.bibliotecanacional.gov.co/>. Acesso em: 15 dez. 2015.
} 
livros digitais da Biblioteca Nacional da Colômbia e 'la pieza del mês' (peça do mês - projeto para resgatar tesouros do acervo da Biblioteca Nacional esquecidos ao longo dos anos). Dentre essas subdivisões, destacam-se as ferramentas de aprendizagem, que através da plataforma virtual de aprendizagem Moodle, disponibiliza aos interagentes aulas e treinamentos, com duas vertentes: uma voltada a estudantes, pesquisadores e professores sobre como utilizar fontes primárias em pesquisa, sobre eficácia para pesquisa em bibliotecas, na internet, e em pesquisas escolares, e a outra vertente para apoio aos bibliotecários da Colômbia.

A Biblioteca Nacional da Colômbia também encoraja o uso de Tecnologias de Informação e Comunicação - TIC para a rede nacional de bibliotecas, através de um projeto que engloba 1200 bibliotecas colombianas. A biblioteca mantém um catálogo online especialmente voltado ao público infantil, como também oferece serviços de disseminação seletiva da informação e desenvolvimento de bibliografias sob demanda online.

A preocupação da Biblioteca Nacional em criar Capital Social através de sua conversação com o público é evidente em suas contas de mídias sociais, e, de acordo com os indicadores apontados por Hillenbrand (2005), a biblioteca fomenta Capital Social em seus serviços quando promove engajamento cívico por meio de programas que conseguem reunir cidadãos, quebrando barreiras sociais, como também induzindo a participação com outras comunidades, quando encorajam seus interagentes a construir conteúdo colaborativo em sua wiki e com suas ferramentas de treinamento. Também oferecem informação sem custo a todos os cidadãos apoiando o ideal democrático, como também, encoraja a confiança por meio da inclusão social, principalmente eu seu projeto de incentivo ao uso de TIC pelas bibliotecas públicas, influenciando diretamente a comunidade que está inserida.

\subsection{Biblioteca Nacional da Costa Rica}

A Biblioteca Nacional Miguel Obregón Lizano ${ }^{11}$, a Biblioteca Nacional da Costa Rica, está vinculada ao Sistema Nacional de Bibliotecas e não possui um website institucional próprio, mas tem um espaço dedicado a Biblioteca Nacional no Sistema Nacional de Bibliotecas da Costa Rica (SINABI). Suas informações são divulgadas na página do Facebook e no Twitter do Sistema de Bibliotecas.

As contas nas mídias sociais não são exclusivas da Biblioteca Nacional da Costa Rica, porém servem como meio de divulgação de informação da biblioteca, bem como de todo Sistema. São utilizadas com fim de divulgação e a conta do Twitter é usada como replicador de informações do Facebook.

Dentro do website, o Sistema mantém uma biblioteca digital, que disponibiliza periódicos, livros, música, partituras, humor gráfico, mapas,

\footnotetext{
${ }^{11}$ Disponível em: <http://www.sinabi.go.cr/>. Acesso em: 15 dez. 2015.
} 
fotografia e bibliografias. Já o espaço dedicado a biblioteca mantém apenas informações sobre a biblioteca, sem serviços digitais vinculados exclusivamente a biblioteca.

\subsection{Biblioteca Nacional de Cuba}

A Biblioteca Nacional José Martín ${ }^{12}$, a Biblioteca Nacional de Cuba, possui website institucional próprio e uma página no Facebook desde 2013.

Sua interação no Facebook é voltada para divulgação de serviços, notícias e ações feitas pela biblioteca, com baixo engajamento e conversação com o público.

Quanto aos serviços ofertados em seu website, a biblioteca mantém uma biblioteca digital, com parte de seu acervo digitalizado, uma seção exclusiva sobre literatura cubana, uma sessão especializada ao público infanto-juvenil, fonte de cultura e conhecimento destinada a crianças e jovens. Assim como Argentina, Bolívia, Brasil, Chile e Colômbia, a Biblioteca Nacional de Cuba também faz parte da Biblioteca Digital del Patrimônio Ibero-ameriano. Em seus serviços na biblioteca digital, a Biblioteca Nacional de Cuba fomenta Capital Social apoiando sociais democráticos quando disponibiliza informações sem custo para todos os cidadãos e promovendo alfabetização digital.

\subsection{Biblioteca Nacional de El Salvador}

A Biblioteca Nacional de El Salvador "Francisco Gavidia"13 possui website institucional próprio e uma página no Facebook na categoria organização governamental desde 2012.

A página do Facebook da Biblioteca Nacional de El Salvador tem baixo engajamento e conversação por parte de seu público, que, na grande maioria das postagens, são dedicadas a divulgar notícias e informações sobre a biblioteca na mídia social.

Quanto aos serviços identificados no website, além de seu acervo digital integrar o acervo da Biblioteca Digital del Patrimonio Iberoameriano junto com outros países, está disponível para acesso em seu website, divididos entre livros e revistas. A biblioteca também disponibiliza coleções digitais voltadas a literatura e a história de El Salvador. Assim, de acordo com os indicativos de fomento de Capital Social apontados por Hillenbran (2010), a Biblioteca Nacional de El Salvador impulsiona o Capital Social em seus serviços quando oferece informações sem custo para todos os cidadãos, criando uma cidadania informada.

\footnotetext{
12 Disponível em: <http://www.bnjm.cu/>. Acesso em: 15 dez. 2015.

${ }^{13}$ Disponível em: <http://www.biblioteca.cultura.gob.sv/>. Acesso em: 15 dez. 2015
} 


\subsection{Biblioteca Nacional do Equador}

A Biblioteca Nacional del Ecuador "Eugênio Espeio"14 está vinculada Casa de la Cultura Equatoriana, com página dedicada a instituição da Biblioteca Nacional. Mantém uma página no Facebook na categoria organização governamental desde 2014.

A página da Biblioteca Nacional do Equador é pouco atualizada, com baixa conversação e engajamento por parte dos interagentes. Seus posts ocorrem na média de um a cada três meses e são voltados para divulgação de notícias sobre a biblioteca. Quanto ao website, na página dedicada a Biblioteca Nacional, encontramos apenas informações como missão, visão, história e contato.

\subsection{Biblioteca Nacional da Guatemala}

A Biblioteca Nacional de Guatemala ${ }^{15}$ não possui website institucional próprio, mas possui uma página dedicada a instituição dentro do website do governo da Guatemala. Mantém uma página no Facebook na categoria organização governamental desde 2010.

A página da Biblioteca Nacional da Guatemala possui um baixo nível de conversação e engajamento por parte dos interagentes, devido a sua baixa atualização. Seus posts são dedicados a divulgação de seus serviços e notícias sobre a biblioteca. Quanto ao website, na página dedicada a Biblioteca Nacional, encontramos apenas informações como missão, visão e história, suas salas e acervos e contato.

\subsection{Biblioteca Nacional de Honduras}

A Biblioteca Nacional Juan Ramón Molina ${ }^{16}$ não possui website institucional próprio, possuindo apenas uma página dedicada à instituição dentro do website do Sistema de Informação Cultural - SIC, instituição a que está vinculada. A biblioteca mantém um perfil pessoal no Facebook, o que impossibilitou investigar as métricas do seu perfil na rede. Quanto a sua página estão disponíveis informações sobre a biblioteca, seu funcionamento e contato.

\subsection{Biblioteca Nacional da Jamaica}

A National Library of Jamaica ${ }^{17}$ possui website institucional próprio, onde divulga informações sobre a biblioteca, seus serviços e coleção digital. Mantém uma página no Facebook desde 2009, uma conta no Twitter e um canal no Youtube, desde 2011. Possui uma conta no Flickr desde 2008, onde publica imagens culturais sobre a Jamaica.

\footnotetext{
${ }^{14}$ Disponível em: <http://www.casadelacultura.gob.ec/>. Acesso em: 15 dez. 2015.

${ }^{15}$ Disponível em: <http://www.mcd-bng.tk/>. Acesso em: 15 dez. 2015.

${ }^{16}$ Disponível em: <http://www.sichonduras.hn/>. Acesso em: 15 dez. 2015.

17 Disponível em: <http://www.nlj.gov.jm/>. Acesso em: 15 dez. 2015.
} 
A Biblioteca Nacional da Jamaica não possui um número elevado de seguidores, mas interage com os mesmos em suas redes, tendo uma média alta de engajamentos em sua página e dedica $42,06 \%$ de sua interação no Twitter a responder e compartilhar mensagens de outros interagentes. Quanto a sua conta no Youtube, a biblioteca divulga vídeos produzidos pela instituição, do seu acervo, porém sem periodicidade de publicação.

Quanto aos serviços oferecidos no website, a biblioteca disponibiliza uma biblioteca digital de acesso público, contendo: biografias jamaicanas, coleção de imagens digitalizadas da coleção de fotografias da Biblioteca Nacional da Jamaica, a coleção 'Picture DIS' que é formada por imagens que destacam pessoas, lugares e produtos da Jamaica, hospedada no Flickr, a coleção Motins e Rebeliões, a coleção Slave Trade que é uma bibliografia digital que comemora a abolição do tráfico de escravos nas Índias Ocidentais, e a coleção Google Livros Jamaica, que conta com livros digitalizados pelo Google sobre a Jamaica.

A Biblioteca Nacional da Jamaica fomenta Capital Social enquanto fornece informações históricas e culturais sem custo a todos os cidadãos, promovendo uma alfabetização digital e uma cidadania informada

\subsection{Biblioteca Nacional do México}

A Biblioteca Nacional do México $^{18}$ possui website institucional próprio, onde apresenta seus serviços, notícias, instruções sobre seu funcionamento e contatos. A biblioteca não possui nenhuma mídia social. A biblioteca disponibiliza parte do seu acervo em formato digital, com foco na base de bibliografia mexicana e no catálogo coletivo de fundos antigos. Apesar de fornecer poucos serviços digitais, a Biblioteca Nacional do México fomenta Capital Social quanto disponibiliza informações culturais e históricas sem custo a todos os cidadãos.

\subsection{Biblioteca Nacional de Nicarágua}

A Biblioteca Nacional "Rubén Darío"19 de Nicarágua possui um website institucional próprio, onde divulga informações sobre a biblioteca, funcionamento seu acervo e catálogo. Não possui mídias sociais nem serviços digitais.

\subsection{Biblioteca Nacional do Panamá}

A Biblioteca Nacional de Panamá possui website institucional próprio e uma página no Facebook na categoria organização governamental desde 2015, e uma conta no Twitter.

Apesar de criar suas contas em mídias sociais recentemente, a Biblioteca utiliza suas contas para divulgar serviços e notícias, porém

18 Disponível em: <http://www.bnm.unam.mx/>. Acesso em: 15 dez. 2015.

19 Disponível em: <http://www.bnrd.gob.ni/>. Acesso em: 15 dez. 2015. 
criam diálogos com seus interagentes, principalmente no Twitter, respondendo e compartilhando os tweets de outros interagentes.

Quanto aos seus serviços, além de participar da Biblioteca Digital do Patrimônio Ibero-americano, a biblioteca disponibiliza em seu website uma coleção digital de acesso público, contendo: bibliografia panamenha, fundo histórico, bibliografia estrangeira, referência, arquivo vertical (coleta de informações a nível nacional, eventualmente sobre questões internacionais, contendo pastas com relatórios e recortes de notícias de jornais, reimpressões, artigos de revistas, convites de eventos, entre outros documentos que ainda não foram publicados em ambientes formais, panamenhos e estrangeiros), coleção audiovisual, em linha, obras especiais e hemeroteca.

Além dos compilados de documentos digitalizados, a biblioteca fornece acesso a Constituição do Panamá, com a legislação desde 1841. A biblioteca também produz coleções e dossiês temáticos especiais, como o catálogo 'El Dorado', a coleção de publicações da Biblioteca Nacional, Artigos Panamenhos, Biblioteca Cultural, coletânea dos acontecimentos marcantes históricos do Panamá, bibliografia dos povos indígenas e, especialmente, o projeto dedicado a informações de gênero, a Biblioteca Digital sobre gênero no Panamá, contendo livros, revistas, cartazes, recortes de imprensa, entre outros, todos relacionados às mulheres e questões de gênero.

Dentro os serviços oferecidos pela Biblioteca Nacional do Panamá, os serviços de informação digital ofertados fomentam Capital Social por proporcionar engajamento cívico, quebrando barreiras sociais e encorajando a tolerância, em especial ao projeto da biblioteca digital sobre gênero. A biblioteca apoia ideais democráticos, oferece informação sem custo a todos os cidadãos, inclusive sobre a legislação do Panamá, promovendo a alfabetização digital e uma cidadania informada.

\subsection{Biblioteca Nacional do Paraguai}

A Biblioteca Nacional del Paraguay ${ }^{20}$ não possui website institucional próprio, sua página está vinculada ao website do Sistema Nacional de Informação Cultural do Paraguai. Mantém uma página no Facebook na categoria organização governamental desde 2014.

A Biblioteca Nacional do Paraguai mantém seu Facebook como forma de divulgar as novidades sobre a biblioteca, suas coleções e serviços. Por não possuir website próprio e sua página no website do Sistema Nacional de Informação Cultural do Paraguai apresentarem apenas informações e contato da biblioteca, sua média de interação se dá por ser o contato oficial direto com a biblioteca.

\footnotetext{
${ }^{20}$ Disponível em: <http://www.spicy.gov.py/>. Acesso em: 15 dez. 2015.
} 


\subsection{Biblioteca Nacional do Peru}

A Biblioteca Nacional del Perú ${ }^{21}$ possui website institucional próprio, onde divulga informações sobre a biblioteca, notícias, eventos, projetos e seu acervo. Mantém uma página no Facebook na categoria organização governamental desde 2009, uma conta no Twitter e um canal no Youtube desde 2009. Possui uma Biblioteca Virtual onde mantém um canal no Youtube sobre o acervo da Biblioteca Virtual e uma conta do Flickr, ambos desde 2013.

A Biblioteca Nacional do Peru mantém um grande número de seguidores em suas mídias sociais, como também mantém uma boa média de engajamento e conversação com seus interagentes. A biblioteca usa suas redes para divulgar informações da biblioteca, seus eventos e informações culturais. Mantém dois canais no Youtube, um da Biblioteca Nacional e outro da Biblioteca Virtual da Biblioteca Nacional do Peru, atualizados mensalmente, com vídeos produzidos pela biblioteca, entrevistas e o acervo da Biblioteca Virtual. Possui uma conta no Flickr onde divulga imagens de seu acervo digital, um blog da Biblioteca Virtual. Além disso, a biblioteca disponibiliza uma biblioteca de links na rede Delicious (mídias sociais que permite ao interagente classificar e catalogar seus websites favoritos e acessá-los de qualquer local). A biblioteca preocupa-se com a divulgação e a interação com os interagentes em suas redes.

Quanto a seu website, a Biblioteca Nacional do Peru disponibiliza a Biblioteca Virtual, projeto que digitaliza o acervo documental e áudio visual, e também compila acervo digital de obras de interesse público. Oferece compilados bibliográficos de autores clássicos do Peru, a coleção Memórias do Mundo, coleção de impressos de 1584 a 1616, registrados na Memória Mundial da UNESCO, além do fundo bibliográfico peruano. Através da Biblioteca Virtual, a Biblioteca Nacional do Peru fomenta Capital Social quando apoia ideais democráticos, oferecendo informação sem custo para todos os cidadãos, promovendo a alfabetização digital e criando cidadania informada.

\subsection{Biblioteca Nacional do Uruguai}

A Biblioteca Nacional de Uruguay 22 possui website institucional próprio, onde divulga informações sobre a biblioteca, notícias, eventos e suas coleções. Mantém uma página no Facebook na categoria organização governamental desde 2013 e uma conta no Twitter.

A Biblioteca Nacional do Uruguai mantém um número elevado de pessoas interagindo com a página no Facebook, vide sua média de engajamento e publicações, em especial, suas postagens e comentários e também com a interação que está na divulgação de serviço e notícias através de sua timeline do Facebook e do Twitter.

\footnotetext{
${ }^{21}$ Disponível em: <http://www.bnp.gob.pe/portalbnp/>. Acesso em: 15 dez. 2015.

${ }^{22}$ Disponível em: <http://www.bibna.gub.uy/>. Acesso em: 15 dez. 2015.
} 
Quanto ao seu website, oferece em seus serviços duas coleções em formato digital, além de participar da Biblioteca Digital de Patrimônio Ibero-ameriano, a Primeiros impressos - coleção da Sala Uruguay, que reúne todo histórico das publicações da Biblioteca Nacional, com documentos históricos sobre a memória do Uruguai, e a coleção 'Obra de Besnes e Irigoyen' - Sala de materiais especiais da Biblioteca Nacional, que disponibiliza aquarelas do cronista gráfico Juan Manuel Besnes e Irigoyen. Enquanto oferece informações apoiados no ideal democrático de informação sem custo para todos os cidadãos, promovendo alfabetização digital, a biblioteca fomenta Capital Social para seu público.

\subsection{Biblioteca Nacional da Venezuela}

A Biblioteca Nacional da Venezuela ${ }^{23}$ possui website institucional próprio, onde divulga informações sobre a biblioteca, notícias, eventos e mantém suas coleções digitais. A biblioteca mantém uma página no Facebook na categoria organização governamental desde 2008, uma conta no Twitter, um canal no Youtube desde 2015, uma conta na mídia social Instagram, uma conta no SoundCloud e um blog integrado ao seu website.

Os números de interagentes que curtem e seguem as contas da Biblioteca Nacional da Venezuela no Facebook e Twitter são baixos, porém a biblioteca tem uma média elevada de interação e engajamento que, na análise das contas junto com os dados métricos coletados, verificou-se que as publicações em sua timeline são feitas por seus interagentes através de compartilhamento na página e não pela biblioteca, o que explica os números elevados de publicações. Quanto ao Twitter, a biblioteca tem um número considerável de compartilhamento de mensagens, 34,75\% de retweets, o que explica a média elevada de tweets por dia. Seus tweets funcionam como divulgação de notícias e projetos da biblioteca. Sobre o canal do Youtube, a biblioteca nacional possui apenas um vídeo publicado. A biblioteca usa sua conta no Instagram para atualizar imagens da biblioteca, eventos e ações. Possui um blog integrado ao website e disponibiliza uma conta no SoundCloud com áudios de poesias. Através de suas mídias sociais verifica-se a preocupação da biblioteca de criar Capital Social interagindo com a comunidade, em especial na mídia social Twitter.

Quanto ao seu website, a biblioteca oferece apenas o catálogo online, não disponibilizando materiais digitais para consulta, ou outros serviços online.

\subsection{Biblioteca Nacional de Trinidad e Tobago}

A National Library and Information System (NALIS) ${ }^{24}$, Biblioteca Nacional de Trinidad e Tobago, possui um website integrado ao sistema de bibliotecas do país, com espaço dedicado exclusivamente a Biblioteca

\footnotetext{
${ }^{23}$ Disponível em: <http://www.bnv.gob.ve/>. Acesso em: 15 dez. 2015.

${ }^{24}$ Disponível em: <http://www.nalis.gov.tt/>. Acesso em: 15 dez. 2015.
} 
Nacional. Mantém uma página no Facebook na categoria organização governamental desde 2008, uma conta no Twitter, um blog e um canal no Youtube, desde 2008.

A página da Biblioteca no Facebook e o perfil no Twitter são integrados ao Sistema de Informação e Bibliotecas do país, fornecendo informações sobre a biblioteca e a rede. Possui um nível interação e conversação nas publicações com uma taxa de respostas de 16,7\% através de comentários. Quanto ao uso do Twitter, em sua maioria, funciona como um replicador das publicações do Facebook, inclusive com links para as postagens da página do Facebook. Em seu canal do Youtube, a biblioteca não publica vídeos há 1 ano.

Quanto aos serviços disponíveis em seu website, a Biblioteca Nacional de Trinidad e Tobago oferece uma biblioteca digital de acesso público, disponibilizando: jornais e clippings de notícias; imagens históricas e culturais de Trinidad e Tobago; calendário NALIS; documentos históricos, coleção de obras de artistas do país, livros, contos e fábulas do país, entre outros documentos. Dos serviços oferecidos na biblioteca digital, destaca-se o Trini Market Place, que é uma coleção de imagens de frutas e vegetais e das tradicionais feiras nos mercados de fim de semana nas ilhas de Trinidad e Tobago. A biblioteca também oferece áudios do projeto 'Storytelling', que se trata de uma coleção de histórias compiladas em contos narrados por mães para seus filhos.

Enquanto a Biblioteca Nacional de Trinidad e Tobago disponibiliza ao seu público, informações culturais e históricas sem custo, ela fomenta Capital Social, promovendo alfabetização digital e uma cidadania informada, como também encorajando a confiança por meio da inclusão social.

\section{Considerações finais}

Das bibliotecas analisadas dos 20 países, percebemos através dos dados coletados que a maioria percebe a importância da interação, seja em suas mídias sociais, no uso das ferramentas de web 2.0 ou nos serviços em seus websites através de ferramentas de web 3.0.

Percebeu-se que as Bibliotecas Nacionais já utilizam recursos de web 2.0 de forma efetiva, como seu canal de divulgação de seus serviços e informações culturais, em especial no uso do Facebook, ferramenta mais utilizada dentre as bibliotecas analisadas (18 bibliotecas). Entre as outras ferramentas de web 2.0, o Twitter é o segundo recurso mais utilizado pelas bibliotecas (12 bibliotecas), e o Youtube é o terceiro recurso de mídia social mais utilizado pelas bibliotecas ( 6 bibliotecas).

Mesmo assim, algumas bibliotecas não identificam seus canais de mídias sociais em seus sites, como o caso da Biblioteca Nacional da Argentina. Em outros casos, as mídias estão integradas ao próprio site, como no caso da Biblioteca Nacional da Bolívia, que disponibiliza abas de interação para Facebook, Twitter, Youtube e Vimeo. 
Sobre o uso do Youtube, verificou-se que as bibliotecas se preocupam em produzir materiais especialmente para seus canais, o que gera um serviço informacional diferenciado das bibliotecas utilizando recursos de web 2.0.

As bibliotecas que mais criam Whuffie através de suas mídias sociais são as bibliotecas nacionais da Argentina, Brasil, Chile, Colômbia, Peru e Uruguai. Nem todas dessas bibliotecas possuem um grande número de seguidores em suas contas, mas se destacam pelos números de engajamento e conversação com seu público.

Das bibliotecas que utilizam ferramentas de web 2.0, as que mais utilizam são, Peru e Venezuela (5 contas em mídias sociais) e Brasil (4 contas em mídias sociais). Destas, na análise dos serviços baseados em web 3.0 em seus websites, apenas a Venezuela não oferece serviços digitais inovadores.

Uma ligação importante entre os dados coletados nas mídias sociais para a construção do Whuffie com os serviços baseados em web 3.0 ofertados nos websites é que quanto mais serviços as bibliotecas oferecem em suas páginas, maior o uso de ferramentas web 2.0, para além do uso dos tradicionais Facebook e Twitter.

Quanto aos serviços baseados em web 3.0 ofertados nos sites das bibliotecas nacionais, as que ofereceram mais serviços inovadores foram as bibliotecas da Argentina, Brasil, Colômbia, Peru, Uruguai e Trinidad Tobago.

Muitas dessas bibliotecas demonstraram novas formas de divulgar e compartilhar informações culturais e históricas sobre seus países, mas, algumas destacam serviços que fomentam capital social através da oferta de informações que promovam igualdade e cidadania. Como indicou Hillenbrand (2005), nosso ponto de análise dos dados, as bibliotecas fomentam capital social quando proporcionam engajamento cívico entre cidadãos independente de idade, sexo, etnia, status econômico, cultura e crenças, quando quebram barreiras sociais e encorajam tolerância e quando apoiam ideais democráticos, pontos esses encontrados em muitos desses serviços hospedados nos websites dessas bibliotecas.

Vale ressaltar que das 20 bibliotecas analisadas, apenas as bibliotecas do México e Nicarágua não possuíam contas em mídias sociais. Já quanto aos serviços baseados em web 3.0, as bibliotecas que não oferecem tais serviços são as de Costa Rica, Equador, Guatemala, Honduras, Nicarágua, Paraguai e Venezuela.

Feita a análise das bibliotecas nacionais do continente latino americano, retomando a inquietação norteadora deste estudo, que buscou entender como as Bibliotecas Nacionais desenvolvem produtos e serviços com a contribuição da web 2.0 e 3.0 e como esses serviços ajudam as bibliotecas a fortalecer o Capital Social com seus interagentes, pode-se constatar que estas bibliotecas, em sua maioria, pouco utilizam suas mídias e sites para oferecer serviços que fomentem Capital Social entre seus interagentes, levando em consideração que a maior parte de suas postagem de conteúdo em mídias são para divulgação e fins 
administrativos, e em seus sites se limitam a oferecer parte do seu acervo em formato digital.

\section{Referências}

BELLING, A. et. al. Exploring library 3.0 and beyond. 2011. Disponível em: <http://www.libraries.vic.gov.au/downloads/20102011_Shared_Leadershi p_Program_Presentation_Day_exploring_library_3.pdf $>$ Acesso em: 14 set. 2013.

BOURDIEU, P. Escritos de educação. Organizado por Maria Alice Nogueira e Afrânio Catani. Petrópolis: Vozes, 2011.

CORRÊA, E. C. D. Usuário, não! Interagente: proposta de um novo termo para um novo tempo. Encontros Bibli., v. 19, n. 41, p. 23-40, set./dez. 2014. Disponível em: $<$ https://periodicos.ufsc.br/index.php/eb/article/viewFile/15182924.2014v19n41p23/28292>. Acesso em: 6 nov. 2015.

FUNDAÇÃO BIBLIOTECA NACIONAL. Biblioteca pública: princípios e diretrizes. 2. ed. rev. e ampl. Rio de Janeiro: Fundação Biblioteca Nacional; Sistema Nacional de Bibliotecas Públicas, 2010. 173 p.

HILLENBRAND, C. Public libraries as developers of social capital. APLIS, v. 18, n.1, p. 4-12, mar. 2005.

HUNT, T. O poder das redes sociais: como o fator Whuffie - seu valor no mundo digital pode maximizar os resultados de seus negócios. São Paulo: Gente, 2010. 266 p.

MACIEL FILHO, A. R. Capital Social e bibliotecas públicas: estudos empíricos. Perspectivas em Ciência da Informação, v. 15, n.2, p. 73-88, maio/ago. 2010.

MATOS, H. Capital social e comunicação: interfaces e articulações. São Paulo: Summus, 2009.

MEDEIROS, D. Bibliotecas nacionais do continente americano sob a perspectiva dos serviços utilizando Web 2.0 E Web 3.0. 2015. 184f. Dissertação (Mestrado em Gestão de Unidade em Informação) - Programa de Pós-Graduação em Gestão da Informação, Universidade do Estado de Santa Catarina, Florianópolis, 2015.

O'REILLY, T. What is Web 2.0. 2005. Disponível em: <http://www. oreillynet. com/pub/a/oreilly/tim/news/2005/09/30/what-is-web-20>. Acesso em: 15 out. 2014.

RECUERO, R. Capital social e redes sociais na internet. 2009. Disponível em: <http://www.raquelrecuero.com/arquivos/2009/05/capital-social-1.html>. Acesso em: 24 jun. 2014.

RECUERO, R.; ZAGO, G. Em busca das "redes que importam": Redes Sociais e Capital Social no Twitter. In: CONGRESSO DA COMAPÓS, 19., Minas Gerais, jun. 2009. Anais... Disponível em: 
<http://www.revistas.univerciencia.org/index.php/libero/article/viewFile/6787/6129>. Acesso em: 27 ago. 2015.

UNESCO. Manifiesto de la UNESCO a favor de la biblioteca pública. Paris: UNESCO, $1994 . \quad$ Disponível em: <http://www.unesco.org/webworld/libraries/manifestos/libraman_es.html>. Acesso em: 27 out. 2013.

WARSCHAUER, M. Comparing face-to-face and electronic communication in the second language classroom. CALICO Journal, v. 13, n. 2, 1996. 